\title{
CUSTOS SOCIAIS
}

\author{
Social costs
}

\section{Sylvio Péllico Netto ${ }^{1}$, Saulo Henrique Weber ${ }^{2}$}

${ }^{1}$ Engenheiro Florestal, Dr., Professor Titular da PUCPR. Curitiba, PR - Brasil. e-mail: pellico.sylvio@pucpr.br

${ }^{2}$ Matemático, M. Sc. Bolsista de doutorado CNPq. Curitiba, PR - Brasil. e-mail: sauloweber@gmail.com

\section{Resumo}

Custos sociais, considerados aqueles resultantes do reparo aos danos causados à natureza, ou socorro às vítimas de fenômenos naturais adversos, são resultantes de ação antrópica e, conseqüentemente, em últimas circunstâncias, o homem é o causador deles e a própria vítima de suas inconseqüentes ações. Destaca-se no presente trabalho algumas fontes importantes de geração de custos sociais, principalmente no âmbito da utilização e exploração da natureza e nos processos de produção agropecuária e industrial. Exemplificando-se fontes geradoras de custos sociais, pode-se destacar suas origens na aceleração da exploração dos recursos naturais, mais especificamente o corte das florestas para ampliação das fronteiras agropecuárias; ampliação das grandes aglomerações urbanas, com conseqüentes ocupações inapropriadas em áreas inadequadas para habitação, como em encostas íngremes ou sujeitas à inundações; uso crescente de produtos poluidores no processo produtivo na agricultura e, finalmente, a poluição da atmosfera pelas emissões industriais. Custos sociais quase sempre são pagos pelo estado e, conseqüentemente, pelos contribuintes. Aventa-se como alternativa a essa realidade a adoção do conceito "usuário-pagador", ou seja, embutir no preço dos produtos os custos sociais gerados por eles. Na nossa percepção, tal proposição não reduziria a poluição produzida por eles a curto prazo, porém contribuiria para gerar mudança de hábitos de consumo na população, que poderia optar pelo uso de produtos produzidos em condições ambientalmente melhores.

Palavras-chave: Ambiente; Agropecuária; Usuário-pagador. 


\begin{abstract}
Social costs, as those resulting from repair the damage to nature, or assistance to victims of adverse natural phenomena, are caused by human action, and therefore in final circumstances, the man is causing them and is the victim of its own inconsequent actions. It is emphasized in this work some main sources of generating social costs, particularly about the rational and depredatory use of nature and in the agriculture and industry production processes. Exemplifying the social costs sources, it can highlight its origins in accelerating the exploitation of natural resources, specifically the cutting of forests for border agricultural expansion; expansion of large cities, with consequent inappropriate occupation of areas unsuitable for housing, with a steep hillsides or subject to flooding; growing use of polluting products in the agriculture production process and, finally, the atmosphere pollution by industrial emissions. Social costs are almost always paid by the state and therefore by the taxpayers. It is suggested as an alternative to that reality the adoption of "user-payer" concept, or include in the products price the social costs generated by them. In our perception this proposition does not reduce the pollution produced by them in the short term, but would help to generate change in population consumption habits, who could choose products produced with in better environmental conditions.
\end{abstract}

Keywords: Environment; Agriculture; User-payer.

\title{
INTRODUÇÃO
}

Entende-se por custos sociais aqueles resultantes do reparo aos danos causados à natureza, ou de socorro às vítimas de fenômenos naturais adversos. Adicionalmente a esse conceito está o princípio de poluidor-pagador, conforme fixada pela OECD (1960) (Convention on the Organisation for Economic Co-operation and Development), que é aquele que impõe a ele a obrigação de arcar com as despesas de prevenção, reparação e repressão da poluição. Modernamente tem-se usado o termo "usuário-pagador", pois o termo "poluidor-pagador" traz a falsa idéia de que o simples ato de pagar resolve a questão de poluição e proteção do meio ambiente. Em outras palavras: "pago, logo posso poluir" (BENJAMIN, 1992).

Há uma questão fundamental nesta reflexão: Quem deve pagar pelos danos causados ao meio ambiente e suas conseqüências? O Estado (e conseqüentemente os contribuintes) ou o próprio poluidor?

Nos países em desenvolvimento, muitas ações efetuadas pelo homem são geradoras de custos sociais graves, porque ainda se desrespeita a lei e não se tem cultura para respeitar a natureza. As classes mais pobres são grandes causadores de custos sociais, exatamente porque não ganham o suficiente para viver condignamente, e assim procuram locais inadequados para morar, usam a terra de maneira imprópria, exploram a natureza além do que é racional, entre outros motivos, sem considerar as futuras gerações. Na Conferência Internacional de Estocolmo, em 1972, países em desenvolvimento, entre eles o Brasil, atacaram as diretrizes de controle à poluição. $\mathrm{O}$ argumento utilizado foi: a pior poluição é a pobreza, sendo necessário o desenvolvimento a qualquer preço.

O processo evolutivo de exploração da natureza mostrou ao longo do tempo que grande parte dos problemas dá decorrentes gera custos sociais. Do ponto de vista de desenvolvimento econômico e social, os custos sociais se enquadram como um recurso orçamentário para socorrer catástrofes. Aquelas empresas que realmente se destacarem e se preocuparem com a natureza e que de fato mostrarem algo de concreto socialmente colherão benefícios competitivos e financeiros de forma global (PEREIRA, 2007).

Muitos problemas sociais não deveriam permanecer insolúveis e considerados como um mal inevitável. Muitos acreditam que a miséria é um desígnio de Deus e não se orientam para mudar o seu destino. A exploração racional dos recursos disponíveis faz parte do processo evolutivo, entretanto é 
saliente considerar os almejos dos interessados e, principalmente, o potencial produtivo do local, a fim de gerar um ótimo comum entre os envolvidos: população (humana) e ambiente (fauna e flora) local e global.

Os países desenvolvidos se valem do princípio de que "é melhor prevenir do que remediar". As medidas profiláticas são mais baratas do que as medidas corretivas. Os custos sociais são maiores, porém são também politicamente mais atrativos. O apelo e a sensibilização política para socorrer as vítimas de catástrofes são mais fáceis do que propor a realização de projetos preventivos contra tais ocorrências. Metaforicamente pode-se comparar essa questão com a gripe, por exemplo. Ela pode ser facilmente curada nos estágios iniciais, mas se não houver cuidado, o tratamento torna-se caro e demorado, além de extremamente desconfortável. Aqueles que já passaram por este processo certamente se cuidarão nos anos vindouros, tomando ações preventivas. Assim, estão os países "desenvolvidos" que, por um lado, devastaram grandes proporções de seus recursos naturais e agora estão tentando a todo custo repará-los (remediar), e, por outro, buscam prevenir maiores perdas ao pouco que restou.

Esta temática é atual e muito interessante como pesquisa ecológica e social. O acesso às informações concretas de tais custos para o país não é tarefa fácil e dependerá de ações bem articuladas para consegui-las completas e confiáveis.

\section{CUSTOS SOCIAIS NA AGROPECUÁRIA}

A seguir serão apresentados exemplos clássicos de custos sociais e suas implicações. É importante observar e refletir que os custos gerados pela ampliação das fronteiras agroflorestais e pecuárias incidem sobre os recursos florestais naturais, sem ao menos ser entendidas as múltiplas interações existentes entre esses fatores sobre a qualidade de vida da população ali estabelecida.

A prática de agricultura em terrenos íngremes resulta em processo de erosão do solo. De acordo com o Dicionário Livre de Geociências (2007), erosão é o conjunto de processos geológicos que implicam em retirada e transporte do material solto (solo e regolito) da superfície do terreno, provocando o desgaste do relevo, principalmente por meio da água, vento e gelo. Em muitas regiões do país, a perda do solo tornou-se grave problema ambiental, pelo surgimento de voçorocas gigantes (refere-se a ravinas onde o lençol freático foi atingido e que, em função disso, assume uma dinâmica de evolução própria e até certo ponto independente das águas superficiais, dando início ao processo de erosão remontante), causando assoreamento de rios e redução significativa de sua vazão. Neste caso, a criação de programas de abrangência nacional de conservação do solo contribui para o aumento da produtividade de áreas em produção, num contexto de sustentabilidade. Entre eles, pode ser citado o MODERAGRO (Programa de Modernização da Agricultura e Conservação de Recursos Naturais), que tem como objetivos incentivar a correção e adubação dos solos, a recuperação das pastagens degradadas, o uso das várzeas já incorporadas ao processo produtivo e projetos de adequação ambiental de propriedades rurais. Os itens financiáveis são aquisição, transporte, aplicação e incorporação de corretivos (calcário, gesso e outros) e adubação verde; implantação de práticas conservacionistas do solo e de adequação ambiental de propriedades rurais; recuperação de pastagens; e investimentos definidos em projeto técnico específico como necessários à sistematização de várzeas. Nessa linha de crédito, foram disponibilizados em 2003: 840 milhões, 2004: 900 milhões, 2005/2006: 900 milhões; com uma taxa de 8,75\% ao ano até 2006 e de 6,75 em 2007 (BNDES, 2007, INFORMATIVO FRUTICULTURA, 2007).

O desmatamento desordenado de grandes áreas florestais, como vem acontecendo atualmente na Amazônia, provoca prejuízos à biodiversidade e inicia o processo de distúrbios ambientais. Em locais com terrenos íngremes, as chuvas fortes e de longa duração provocam enchentes. Essas geralmente dizimam culturas agrícolas, provocam desabrigo às pessoas que vivem nas áreas afetáveis e, conseqüentemente, geram custos sociais.

Segundo levantamento da FAO (2005) (Food and Agriculture Organization of the United Nations), 13,1 milhões de hectares de florestas por ano foram destruídas no mundo entre 1990 e 2000, e 12,9 milhões entre 2000 e 2005 . O Brasil contribuiu para esse quadro com $21 \%$ (2,75 milhões/ano) no primeiro período e 24\% (3,10 milhões/ano) no segundo, totalizando 42,99 milhões em 15 anos. A 
FAO atribui essa destruição, principalmente, ao crescimento demográfico e à pobreza no meio rural. A FAO revelou ainda que, apesar de nos países desenvolvidos o reflorestamento anual ter sido superior ao desmatamento, a situação é inversa, em termos absolutos, na América Latina, na África e na Ásia. Atualmente, estima-se que é desmatada, a cada ano, uma área do tamanho do estado do Paraná. A Floresta Tropical é destruída à velocidade de meio hectare por segundo.

O desmatamento está associado à abertura de fronteiras para produção de alimentos. Anualmente, são derrubadas ou queimadas muito mais árvores do que plantadas. O déficit florestal do planeta, em 1990, chegou a uma área de $168.000 \mathrm{~km}^{2}$. Considerando-se esse ritmo, nos dias de hoje, a área degradada deve ter já atingido o tamanho de toda a área agrícola dos Estados Unidos, ou mais.

$O$ uso indiscriminado de pesticidas tem provocado cerca de um milhão de casos de envenenamento agudo por ano no mundo. Este caso gera alguns custos sociais irreparáveis. O quadro mundial revela que apenas $11 \%$ da terra estão disponíveis para a produção agrícola.

De acordo com cálculos das Nações Unidas, 32 milhões de quilômetros quadrados da superfície terrestre estão afetados pela desertificação de acordo com Le Houérou (1977), apud Verdum (2001), é diminuição ou destruição do potencial biológico da Terra, que pode ser relacionada a dois fatores: evolução bioclimática ou intervenções antrópicas, substituindo a paisagem vegetal por outra abiótica e com geodinâmica nova (VERDUM et al., 2001). O aumento das áreas desertas deve-se à retirada da cobertura florestal em áreas onde o solo não tem condições de ser apropriado a outros usos que não o florestal. Esses solos são geralmente arenosos, de baixa fertilidade e facilmente erodíveis. No Brasil, existem algumas áreas que já mostram início de um processo de desertificação, uma no Rio Grande do Sul, uma no Nordeste e uma na Amazônia. Em alguns livros de história, consta que á área do grande deserto de Saara na África já foi coberto por florestas.

Apesar de Marchiori (1992) afirmar que a presença e a expansão dos areais no sudoeste riograndense é anterior aos primórdios da colonização e reside na fragilidade natural do ecossistema, Azevedo e Kaminski (1995) citam que essa fragilidade natural deriva da extrema dificuldade do solo local em compensar as perturbações impostas pelo e ao meio ambiente, o que pode ser notado pela precariedade na permanência da vegetação, baixa capacidade de fornecimento e retenção de nutrientes e alta susceptibilidade à erosão hídrica e eólica. Segundo Freitas, Goulart e Alves (2002), trabalhando com avaliação das propostas de recuperação, a melhor opção seria a implantação de florestas de eucalipto, não só pelos benefícios que essa pode gerar ao meio ambiente em um curto espaço de tempo, mas pela possibilidade de reincorporação e, em alguns casos, incorporação das terras afetadas ao processo produtivo com algum retorno econômico.

Conforme Lima (1999), nos trópicos está concentrada a maior diversidade de espécies. Ele afirma que é necessário criar consciência sobre o valor e condições dos recursos genéticos florestais nestas regiões, principalmente no semi-árido, onde o problema de desertificação avança em função de fatores antrópicos.

A Amazônia Brasileira precisa desenvolver-se e oferecer qualidade de vida aos amazonenses, porém isso somente será possível se forem mantidos pelo menos os $80 \%$ de cobertura florestal exigidos pelo código florestal brasileiro, sob pena de se tornar um grande deserto. A população ali estabelecida tira seu sustento dos recursos florestais disponíveis, em grande parte de forma ecologicamente sustentável, entretanto na maioria dos casos não é economicamente viável. Os produtos são comercializados localmente, vendidos principalmente para "atravessadores", que os transportam para os grandes centros consumidores. O desejo comum dos moradores é eliminar os intermediários, para que eles tenham seus produtos comercializados nos centros maiores, conseguindo, assim, um maior valor agregado a eles e um retorno financeiro mais justo ao seu esforço como produtor florestal.

Nesta linha de raciocínio, populações ribeirinhas no Brasil são freqüentemente afetadas pelas enchentes dos rios, quando perdem quase todos seus pertences. O contínuo clamor pelo atendimento público ao desabrigo gera também contínuos pagamentos de recursos para superar tais efeitos catastróficos. Enquanto não ocorrer uma proposta para limitar a vida em áreas passíveis de 
alagamento, estaremos pagando os custos sociais ao desabrigo. O país necessita sim ter recursos orçamentários para socorrer a população em casos de catástrofes, porém em alguns casos não existe o censo apropriado para se mudar os costumes, com conseqüente redução dos custos sociais. Outro problema grave no país ocorre nas favelas em geral, especialmente nas do Rio de Janeiro e São Paulo. Pessoas cada vez mais se apinham nos morros tentando viver cercados ao coração daquelas cidades, sem, contudo, preocuparem-se com os deslizamentos de terras, por ocasião das grandes chuvas. Quase todos os anos o governo brasileiro está gastando uma razoável soma de recursos para atender as vítimas de tais catástrofes. Sem se reparar o mal pela raiz, não há como reduzir os custos sociais no Brasil.

Tal situação ocorre também com as áreas agrícolas localizadas no polígono das secas no nordeste brasileiro. A estiagem prolongada gera perdas expressivas na produção agrícola das propriedades, afeta ou mata os rebanhos bovinos e resulta em desesperanças ao produtor rural. As soluções para garantir o suprimento de água, como perfuração de poços, construção de açudes, desvio de rios, entre outras, enquadram-se também como custos sociais. Algumas tecnologias mais avançadas desenvolvidas em Israel poderão minorar tais dificuldades, porém são demasiadamente caras, como o caso de irrigação permanente por gotejamento nas plantas, em que se concluiu que as melhores frutas podem ser produzidas por esse procedimento.

Em nossa opinião, um expressivo programa de reflorestamento nas áreas mais adversas do nordeste brasileiro seria uma importante medida para ajudar a recuperar áreas muito degradadas. As florestas ajudariam na formação de microclimas pela respiração das árvores, interceptariam as chuvas para aumento dos lençóis freáticos e ofereceriam madeira para energia, assim como está sendo proposto para o Rio Grande do Sul.

Outro problema ambiental que tem preocupado os países desenvolvidos, mas que já está ocorrendo no Brasil e em outros países em desenvolvimento, é a chuva ácida, que contém o dióxido de enxofre e os óxidos de nitrogênio, resultantes de emissões feitas pelas usinas elétricas movidas a carvão e pelos motores de veículos. Esses produtos na atmosfera entram em reação química e voltam a Terra na forma de chuva ou neve corrosiva, com alta concentração de ácidos. Essa chuva e neve destroem a fauna e a flora dos rios, atinge as florestas e causam até corrosão de edificações e monumentos. As chuvas com pH abaixo de 5,0 é considerada ácida. Na Alemanha, em avaliações efetuadas em algumas regiões, o índice de acidez chegou a 4,3. No Rio de Janeiro já ocorreu chuvas com índice 4,6. O maior problema neste caso é que o vento leva as emissões a quilômetros de distância, o que pode afetar áreas bem distantes do foco poluidor. Informações fornecidas pelo Canadá atestam que a ocorrência de chuva ácida lá já provocou a morte de 14 mil rios e lagos. Na Alemanha, em várias reuniões científicas e governamentais, surgiu a discussão de quem deve ser cobrado pelos prejuízos provocados comprovadamente pelas chuvas ácidas?

\section{CONSIDERAÇÕES FINAIS}

Como se pode depreender desses exemplos, a solução do problema foge até mesmo da aplicação legal, pois o poluidor é muitas vezes de outro país e não há uma maneira de separar as cotas das emissões e atribuí-las aos culpados. O réu neste caso é deletério, na verdadeira acepção dos fatos. Informações geradas pela Alemanha em 1992 afirmam que 2/3 das árvores naquele país estão doentes, principalmente por causa das chuvas ácidas. Para a Europa, as chuvas ácidas custarão US\$ 30 bilhões por ano, equivalente ao preço da madeira em termos das árvores perdidas.

É necessário embutir no preço dos produtos os custos sociais. Produtos cujas produções e resíduos finais são altamente poluentes devem ter associados aos seus preços seus custos sociais. Isso não reduziria a poluição produzida por eles, mas poderia gerar uma mudança de hábitos de consumo por parte da população, que poderiam optar pelo uso de produtos produzidos em condições ambientalmente melhores. 


\section{REFERÊNCIAS}

AZEVEDO, A. C. de; KAMINSKI, J. Considerações sobre os solos dos campos de areia no Rio Grande do Sul. Revista Ciência \& Ambiente, Santa Maria, n. 11, p. 33-55, jul./dez. 1995.

BENJAMIN, A. H. V. O princípio poluidor-pagador e a reparação do dano ambiental. In: ENCONTRO NACIONAL DA ASSOCIAÇÃO BRASILEIRA DE ENTIDADES DE MEIOAMBIENTE (ABEMA): Realidade e perspectivas do sistema nacional de meio ambiente. Palestra... São Paulo. 1992.

BNDES, Banco Nacional de Desenvolvimento Econômico e Social. Disponível em: <http:// www.bndes.gov.br/noticias/2004/not861.asp>. Acesso em: 22 abr. 2007.

DICIONÁRIO LIVRE DE GEOCIÊNCIAS. Disponível em: < http://www.dicionario.pro.br/>. Acesso em: 10 fev. 2007.

FAO - Food and Agriculture Organization. Global forest resources assessment: progress towards sustainable forest management. Roma: Publishing Management Service Information Division FAO. 2005. 350 p.

FREITAS, C. A.; GOULART, D. D.; ALVES, F. D. O processo de arenização no Sudoeste do Rio Grande do Sul: uma alternativa para o seu desenvolvimento sócio-econômico. In: ENCONTRO DE ECONOMiA GAÚCHA, 1., 2002, Porto Alegre. Anais... Porto Alegre: Porto Alegre. 2002.

INFORMATIVO FRUTICULTURA. Ano 1, v. 11, jul. 2007. Disponível em: <http:// www.br.sgs.com/pt_br/ssc_informativo11_fruticulturaa_1_.pdf>. Acesso em: 15 ago. 2007.

LIMA, P. C. F. Recursos genéticos e evolução do gênero Prosopis no Nordeste do Brasil. In: QUEIROZ, M. A.; GOEDERT, C. O.; RAMOS, S. R. R.. (Org.). Recursos genéticos e melhoramento de plantas para o Nordeste brasileiro (on line). Versão 1.0. Petrolina, PE: Embrapa semi-árido/Brasília: Embrapa Recursos Genéticos e Biotecnologia, set. 1999.

MARCHIORI, J. N. C. Areais do Sudoeste do Rio Grande do Sul: Elementos para uma História Natural. Revista Ciência \& Ambiente, Santa Maria, n. 5, p. 65-89, jul./dez, 1992.

OECD, Convention on the Organisation for Economic Co-operation and Development. Paris: 1960. Disponível em: 0 <http://www.oecd.org/document/7/ 0,3343,en_2649_34483_1915847_1_1_1_1,00.html>. Acesso em: 13 mar. 2007.

PEREIRA, A. R. Economia ambiental e gestão da sustentabilidade. Disponível em: < http:// www.artigocientifico.com.br/uploads/artc_1158352553_37.doc>. Acesso em: 15 abr. 2007.

VERDUM, R. et al. Desertificação: questionando as bases conceituais, escalas de análise e conseqüências. Geographia, Niterói, n. 6, 2001.

Recebido: 09/05/2006

Received: 05/09/2006

Aprovado: $31 / 10 / 2007$

Approved: $10 / 31 / 2007$ 